\title{
Connection between participation in an interactive learning environment and learning through teamwork
}

\author{
Binod Nainabasti ${ }^{1}$, David Brookes ${ }^{1}$, Yuehai Yang ${ }^{2}$, Yuhfen Lin \\ ${ }^{1}$ Florida International University, Department of Physics, \\ 11200 SW ${ }^{\text {th }}$ St, CP 204, Miami, FL, 33199 \\ ${ }^{2}$ California State University, Chico, Department of Physics \\ Chico, CA, 95929-0202
}

\begin{abstract}
Research has shown that an Interactive Learning Environment (ILE) can be an effective learning environment for acquiring transferrable knowledge. Our research analyzed the relationship between students' participation in different areas of two consecutive ILE physics classes that implemented the Investigative Science Learning Environment (ISLE) curriculum, a type of widely used ILE, and their ability to learn new physics through teamwork. We quantified students' participation in two areas: in-class learning-activities and class review sessions. To measure students' ability to learn through teamwork, we gave them "group exams" that presented real life scenarios that could only be understood using physics they had not yet learned. We then gave them standard physics problems related to the group exam problems to solve individually. Our results suggest that successful students built an effective habit of teamwork learning through participating in group learning activities, whereas students who were disengaged in review did not perform well in these teamwork learning activities.
\end{abstract}

PACS: $01.40 . \mathrm{Fk}, 01.40 . \mathrm{Ha}$

\section{INTRODUCTION}

Interactive learning has received considerable attention over the past several years. Several researchers and government agencies have called for the reform of standard lecture delivery by incorporating active learning in the classroom [1]. They believe that interactive learning environments help students to (1) integrate basic concepts into conceptual frameworks, (2) link prior learning to new knowledge, (3) develop scientific reasoning and problem solving skills that support the application of concepts to new situations, (4) enhance critical thinking, develop highlevel thinking processes, and shift students' attitudes $[2,3,4]$.

In the process of video analysis for our larger project examining the role of students' interaction in reformed physics classes, we have noticed that there are many differences in students' behavior during interactions in learning activities in an Interactive Learning Environment (ILE). For example, some students mostly talked about the topic under discussion, some remained quiet or did not know what they were doing, and some were frequently involved in off-topic conversations. Besides investigating the ways in which students participate, we would like to investigate how these behaviors are related to students' ability to learn through teamwork. Therefore, this paper is an empirical analysis, examining the relationship between students' participation in different areas of two consecutive ILE physics classes that implemented the Investigative Science Learning Environment (ISLE) curriculum, a type of widely used ILE, and their ability to learn a new physics topic to solve novel problems through teamwork.

\section{THEORETICAL FRAMEWORK}

The theoretical basis for expecting relationships between students' participative behaviors in an ILE and their learning ability through teamwork comes from social cognitive theories of learning, coupled with constructivism theory.

Three variables of social cognitive theory (behavioral, environmental and personal factors) interact with each other, causing learning to occur [5]. In this paper we will focus on in-class behavioral factors and their role in the learning process. Active learning is identified as an important principle of constructivism. A constructivist approach in teaching and learning requires one to change various habitual ways for thinking and participating in an active learning environment [6]. In other words, it requires behavioral change. In the participationist framework, learning is an ongoing process of transformation of participation in which people contribute support and direction in shared endeavors [7]. Researchers understand transformation of knowledge through participation as "the idea that learning and development occur as people participate in the socio-cultural activities of their community, transforming their understanding, roles and responsibilities as they participate" [7]. In Vygotsky's view, peer interaction is an important way to facilitate individual cognitive growth and knowledge acquisition, and peer collaboration can help learners in problem solving [8]. 


\section{METHODOLOGY}

Participants for this study were drawn from students enrolled in an introductory physics I \& II with calculus sequence at Florida International University (FIU) in Fall 2013 and Spring 2014. This course used a studio-like format with integrated lab and lecture, implementing the ISLE philosophy [9] with 30 (11 females and 19 males) in Fall, and 26 (9 females and 17 males) students in Spring. The majority of students were Hispanic, consistent with the overall demographics of FIU. The ISLE course operated as a collaborative learning environment and focused on conceptual reasoning and the development of scientific habits of mind [9].

To evaluate students' ability to learn through teamwork (teamwork learning), we gave students a group exam [10] two days before each class individual exam, three times in each semester. The group exams involved problems that had to be solved by the class as a whole using physics they had not yet learned. Students were allowed to use any resources at their disposal and handed in one solution per group of 3 students. For each individual exam, we embedded one problem related to the group exam problem they had completed two days earlier. One example of a group exam and a corresponding individual exam question is presented below.

Group Exam: (1) Consider an object traveling in a circle at a constant speed. Find the direction of the object's acceleration at any point on its circular path. Explain how an object can have an acceleration if the speed is constant. (2) Starting from what you already know, $\vec{a}=\frac{\Delta \vec{v}}{\Delta t}$, what you found in part a), and anything else you can find, find an algebraic expression for the acceleration of an object traveling in a circle of radius $r$ with a constant speed $v$. (3) Come up with three everyday examples of an object traveling in a circle at a constant rate. Perform the actual experiments or watch videos. (A rollerblading instructor is at your disposal if you require him.) Draw a force diagrams for the object that is moving in a circle at various points in its motion. In each case identify the direction of the object's acceleration and the direction of the net force exerted on the object by other objects. Identify a pattern if you can. 4) As a class, come to an agreement as to how you can formulate Newton's second law for an object traveling in a circle at a constant speed. Explain and discuss your formulation.

Individual Exam: An object is spinning in a vertical circle attached to a spring scale that is free to spin around a fixed metal post. When the object is hanging from the scale with nothing moving or spinning, the scale reads 39.2 $N$. Then we spin the object in a vertical circle. Find the reading on the scale when the object is at the base of the circle (at the point shown in the Figure 1), if it has a speed of $6 \mathrm{~m} / \mathrm{s}$ at that point.

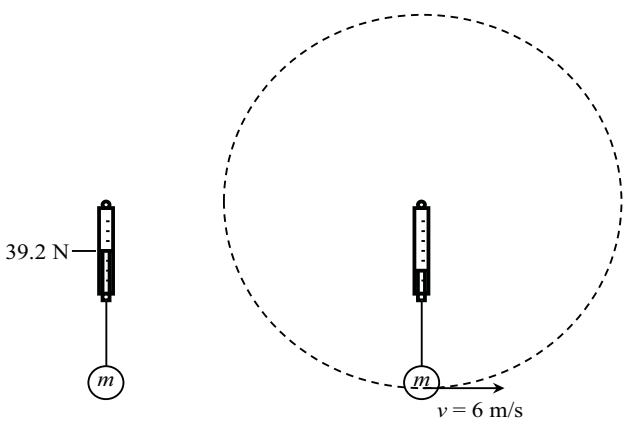

FIG. 1. An object is spinning in a vertical circle.

To quantify students' participation in the ILE, we chose to examine two aspects of the ISLE class; (a) In-class Learning Activities and (b) Review Session, which happened at the beginning of every class.

Learning Activities (LAs): The instructor ran the class according to the sequences of the ISLE learning cycle using a set of worksheets based on the Active Learning Guide [11]. The contents of these worksheets are what we refer to as LAs. We videotaped a number of episodes throughout the two semesters of students working together in groups on specific LAs.

Six episodes from the Fall and three episodes from the Spring semesters were selected based on the level of difficulty of the LAs. We categorized students' behavior in learning activities into four categories (described in Table I) and coded them into these four categories in 30-second intervals.

TABLE I: Coding scheme for learning activities

\begin{tabular}{|c|c|c|}
\hline Code & Category & Description \\
\hline 1 & $\begin{array}{l}\text { Participa- } \\
\text { ting }\end{array}$ & $\begin{array}{l}\text { Communicating with other students, } \\
\text { instructors or learning assistants in audible } \\
\text { words regarding the physics subject. }\end{array}$ \\
\hline 2 & Off-topic & $\begin{array}{l}\text { Communicating with other students, } \\
\text { instructors or learning assistants in audible } \\
\text { words about anything but the subject. }\end{array}$ \\
\hline 3 & $\begin{array}{l}\text { Writing or } \\
\text { Drawing }\end{array}$ & $\begin{array}{l}\text { Writing or drawing on papers or } \\
\text { whiteboards without speaking to others. }\end{array}$ \\
\hline 4 & Uncodable & $\begin{array}{l}\text { Behaviors/activities that do not fit any of } \\
\text { the three specific categories above. }\end{array}$ \\
\hline
\end{tabular}

We coded 45 videos of which each was on average 15 minutes long in total. A single code was given for each 30second time segment based on a superseding policy which is defined as follows: If a student engaged in discussion or conversation related to the assigned activity, we assigned them code 1 no matter how much time they spent talking about the physics topic during that 30 -second interval. We assigned code 2 for a time interval only if there were no audible words related to the physics topic, but the student was involved in an off-topic conversation. We assigned code 3 if there were no audible words related to physics or off-topic conversations, but the student was writing or drawing on paper or whiteboards. When behaviors of 
students did not fit any of these first three categories, then we assigned them code 4 [12]. Two coders coded videos of LAs. Randomly selected samples were chosen to evaluate inter-rater reliability. On these samples a Cohen's Kappa of 0.78 (a high level substantial agreement) was achieved [13].

Review Session (RS): Each class throughout two semesters started with a review session where the entire class worked together and anyone could participate. Review sessions were structured around two questions "what did we learn last class?" and "did anything remain unclear?" Sessions usually lasted 15-20 minutes and were largely student-directed with minimal intervention from the instructor. We coded the review session in real time without videotaping according to the coding scheme described in Table II and adopted the same superseding policy as in LAs. Each student was assigned a single code for the entire review session.

TABLE II: Coding scheme for review sessions

\begin{tabular}{|c|c|c|}
\hline $\mathrm{Cd}$ & Category & Description \\
\hline 1 & Participating & $\begin{array}{l}\text { Engaging in review activities in different } \\
\text { ways. E.g.: Reminding what they did in the } \\
\text { last class, answering and explaining } \\
\text { questions, presenting and challenging } \\
\text { ideas, or facilitating the review session. }\end{array}$ \\
\hline 2 & Disengaged & $\begin{array}{l}\text { Engaging in activities not related to the } \\
\text { review session with clear evidence of not } \\
\text { paying attention to the review session. For } \\
\text { example: texting, surfing online, doing } \\
\text { homework, etc. }\end{array}$ \\
\hline 3 & Uncodable & $\begin{array}{l}\text { Taking notes about the subject under } \\
\text { review, apparently paying attention without } \\
\text { speaking, sitting with no evidence of any } \\
\text { active involvement in the review session } \\
\text { without participating or being disengaged. }\end{array}$ \\
\hline
\end{tabular}

We defined each students' average score on the individual exam questions related to the group exam problems as "teamwork learning". To investigate the relationship between participation in LAs and RSs, and students' teamwork learning, we applied Pearson's productmoment correlation, examining the relationship between the frequency of each type of behavior and students' teamwork learning.

\section{RESULTS}

Figure 2 shows percentage of the total coded instances that comprise each of the coding categories of LA and RS during the Fall and Spring semesters. We then examined the relationship between students' participation in LA, RS, and teamwork learning. The results of this analysis are presented in Tables III and IV.

Results in Table III demonstrate that categories of student's behaviors in LAs have varying levels of correlation with teamwork learning. Only the
"Participating" code has a consistently positive, significant relation to teamwork learning across two semesters.

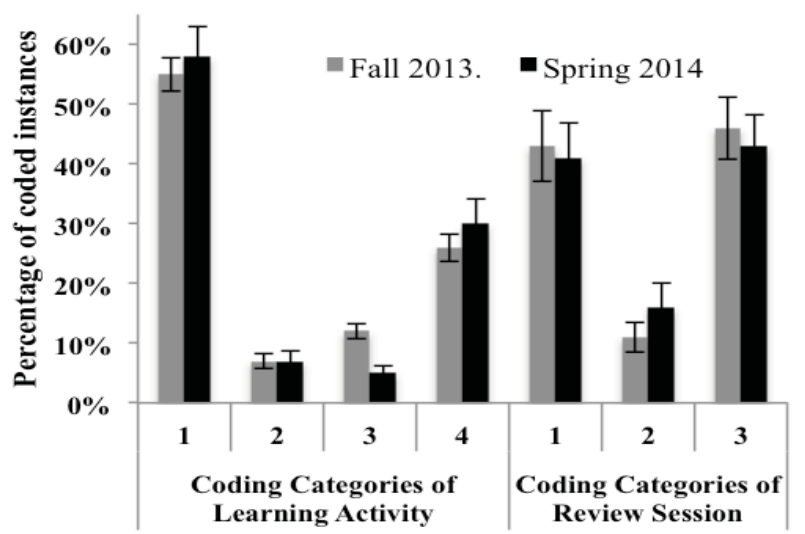

FIG. 2. Percentage of the total coded instances that comprise each of the coding categories of LA and RS.

TABLE III: Pearson's correlation between different forms of participation categories in LA and teamwork learning.

\begin{tabular}{cllll}
\hline \hline Code: & 1 & 2 & 3 & 4 \\
\hline Fall & $\mathrm{r}=0.40^{*}$ & $\mathrm{r}=-0.25$ & $\mathrm{r}=0.02$ & $\mathrm{r}=-0.40^{*}$ \\
2013 & & & & \\
$\begin{array}{c}\text { Spring } \\
2014\end{array}$ & $\mathrm{r}=0.44^{*}$ & $\mathrm{r}=-0.66^{* *}$ & $\mathrm{r}=0.05$ & $\mathrm{r}=-0.27$ \\
\hline \hline & & & \\
\hline *p $<0.05, * * \mathrm{p}<0.005, \mathrm{~N}($ fall $)=30, \mathrm{~N}$ (spring) $=26$ &
\end{tabular}

In RS, only the "Disengaged" code had a consistently negative relation with teamwork learning as shown in Table IV.

TABLE IV: Pearson's correlation between different forms of participation categories in RS and teamwork learning

\begin{tabular}{clll}
\hline \hline Code: & 1 & 2 & 3 \\
\hline Fall & $\mathrm{r}=0.26$ & $\mathrm{r}=-0.47^{* *}$ & $\mathrm{r}=-0.32$ \\
2013 & & & \\
Spring & $\mathrm{r}=0.29$ & $\mathrm{r}=-0.76^{* * *}$ & $\mathrm{r}=0.09$ \\
2014 & & & \\
\hline \hline$* * \mathrm{p}<0.005, * * * \mathrm{p}<0.0005, \mathrm{~N}($ fall $)=30, \mathrm{~N}$ (spring) $=26$
\end{tabular}

One of the primary questions in our research is whether students' participation changes and how robust their patterns of participation are from semester to semester. There were 20 students in common between the Fall and Spring semesters. In the Spring semester we mixed the groups so that no student in the Spring semester was with a group partner from the Fall semester. We then examined the relationship between students' participation in LAs between the Fall and Spring semesters. We found a significant correlation $(r=0.68, p=0.001)$ between the amount that each student participated in LAs in the Fall and the Spring semester. See Figure 3. 


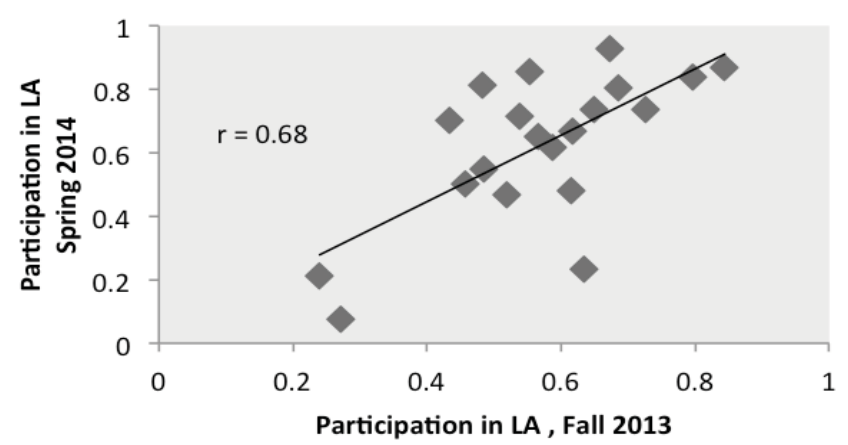

FIG. 3. Relationship between percentage of participation code in LAs in the Fall semester and the Spring semester.

\section{DISCUSSION AND CONCLUSION}

Although the sample size of our study is small, the consistent relationships we found across two semesters lends some confidence to our results. Participating in LAs has significant correlation with teamwork learning. In addition, there is a significant correlation between participation in LAs during the Fall semester, and in the Spring semester. Taken together, these two results suggest to us that a) productive/unproductive collaborative habits formed during in-class learning activities carry over to the collaborative exam context, and b) once students have established how to work successfully in a highly collaborative ILE, these habits of collaboration transfer over from one semester to another, irrespective of who the students work with. While it is possible that students learned to learn collaboratively elsewhere, we find this hypothesis unlikely. Students entering our class have great difficulty adapting to the ILE and it takes persistent effort on the part of the instructors to shift students from passive

[1] National Research Council, Improving Undergraduate Instruction in Science, Technology, Engineering, and

[2] A. Sivan, R. Wong Leung, C. Woon, and D. Kember, Inn. Educ. Train. Int. 37, 381-389 (2000).

[3] NSF, Shaping the Future: New Expectations for Undergraduate Education in Science, Mathematics, Engineering, and Technology (1996).

[4] C.C. Bonwell and J.A. Eison, Active Learning: Creating Excitement in the Classroom (The George Washington University, School of Education and Human Development, Washington, D.C., 1991).

[5] B.J. Zimmerman, J. Educ. Psych. 81, 329-339 (1989).

[6] S. Gulati, Inn. Educ. Teach. Int. 45, 183-192 (2008).

[7] B. Rogoff, Apprenticeship in Thinking: Cognitive Development in Social Context (Oxford University Press, New York, NY, 1990).

[8] L.S. Vygotsky, Mind in Society: The Development of Higher Psycological Processes (Harvard University Press, Cambridge, M.A., 1978). recipients of knowledge to active participants in their own knowledge construction process.

Another striking result is that being disengaged in the RSs has consistent negative relation with teamwork learning. While we cannot ascribe a causal link between such behaviors and success or failure in the course, we suggest that a mindful instructor could use observations of disengaged students in group discussions as a useful diagnostic tool to identify those at risk of failing in his/her course. In our experience it is easy to help students who are engaged, but challenging to get disengaged students to join more actively in the learning process.

Finally, there is no significant relation between participation in RSs and teamwork learning. In previous research [12] we found that students' participation in RS was significantly correlated with growth of conceptual understanding as measured by the Force Concept Inventory. Therefore, in future work, we will take a closer look at the "participation" category of RS. We suggest that the lack of correlation between participation in RS and teamwork learning may occur because RSs offers fewer chances to get involved in discussion since the entire class worked together during the RS. In future work we are going to analyze students' participation patterns in RS one more semester in a large interactive learning class. This analysis will allow us to make more convincing suggestions about the impact of learning how to interact and collaborate effectively with each other in a highly interactive learning environment.

\section{ACKNOWLEDGEMENTS}

We would like to thank all members of PER Group at FIU for their feedback and encouragement. This research is supported by NSF grant \# 0802184 .

[9] E. Etkina and A. Van Heuvelen, in Research-Based Reform of University Physics, edited by E.F. Redish and P.J. Cooney (2007).

[10] Y. Lin and D.T. Brookes, in Proceedings of the 2012 Physics Education Research Conference, edited by P.V. Engelhardt, A.D. Churukian, and N.S. Rebello (AIP Con. Pro. Melville, NY, 2013), pp. 254-257.

[11] A.V. Heuvelen and E. Etkina, The Physics Active Learning Guide, Student Edition (Pearson Addison Wesley, San Francisco, 2006).

[12] B. Nainabasti, D.T. Brookes, and Y. Yang, in Proceedings of the 2014 Physics Education Research Conference, edited by P.V. Engelhardt, A.D. Churukian, and D.L. Jones (AIP Conference Proceedings, Melville, NY, 2015), pp. 195-198.

[13] McHugh M. L. Interrater reliability: the kappa statistic. Biochemia Medica. 22(3), 276-282 (2012). 